University of Nebraska - Lincoln

DigitalCommons@University of Nebraska - Lincoln

$12-16-2008$

\title{
A modeling and spatio-temporal analysis framework for monitoring environmental change using NPP as an ecosystem indicator
}

\author{
Robert Crabtree \\ Yellowstone Ecological Research Center, crabtree@yellowstoneresearch.org \\ Christopher Potter \\ NASA Ames Research Center, chris.potter@nasa.gov \\ Randall Mullen \\ Yellowstone Ecological Research Center \\ Jennifer Sheldon \\ Yellowstone Ecological Research Center \\ Shengli Huang \\ Yellowstone Ecological Research Center
}

See next page for additional authors

Follow this and additional works at: https://digitalcommons.unl.edu/nasapub

Part of the Physical Sciences and Mathematics Commons

\footnotetext{
Crabtree, Robert; Potter, Christopher; Mullen, Randall; Sheldon, Jennifer; Huang, Shengli; Harmsen, Joshua; Rodman, Ann; and Jean, Cathie, "A modeling and spatio-temporal analysis framework for monitoring environmental change using NPP as an ecosystem indicator" (2008). NASA Publications. 22. https://digitalcommons.unl.edu/nasapub/22
}

This Article is brought to you for free and open access by the National Aeronautics and Space Administration at DigitalCommons@University of Nebraska - Lincoln. It has been accepted for inclusion in NASA Publications by an authorized administrator of DigitalCommons@University of Nebraska - Lincoln. 


\section{Authors}

Robert Crabtree, Christopher Potter, Randall Mullen, Jennifer Sheldon, Shengli Huang, Joshua Harmsen, Ann Rodman, and Cathie Jean 


\title{
A modeling and spatio-temporal analysis framework for monitoring environmental change using NPP as an ecosystem indicator
}

\author{
Robert Crabtree $^{\mathrm{a}, \mathrm{d}, *}$, Christopher Potter ${ }^{\mathrm{b}}$, Randall Mullen ${ }^{\mathrm{a}}$, Jennifer Sheldon ${ }^{\mathrm{a}}$, Shengli Huang ${ }^{\mathrm{a}}$, \\ Joshua Harmsen ${ }^{\mathrm{a}}$, Ann Rodman ${ }^{\mathrm{c}}$, Cathie Jean ${ }^{\mathrm{c}}$ \\ a Yellowstone Ecological Research Center, 2048 Analysis Drive, Bozeman, MT 59718, United States \\ b NASA Ames Research Center, Moffett Field, CA 94035, United States \\ c Yellowstone Center for Resources, Yellowstone National Park, WY 821990, United States \\ d Department of Ecosystem and Conservation Sciences, College of Forestry and Conservation, University of Montana, 32 Campus Drive, Missoula, MT 59812, United States
}

\section{A R T I C L E I N F O}

\section{Article history:}

Received 11 December 2007

Received in revised form 8 December 2008

Accepted 16 December 2008

\section{Keywords}

Ecosystem indicators

Spatio-temporal analysis

NPP

MODIS

NASA-CASA

Vegetation moisture stress

\begin{abstract}
A B S T R A C T
We present and describe a modeling and analysis framework for monitoring protected area (PA) ecosystems with net primary productivity (NPP) as an indicator of health. It brings together satellite data, an ecosystem simulation model (NASA-CASA), spatial linear models with autoregression, and a GIS to provide practitioners a low-cost, accessible ecosystem monitoring and analysis system (EMAS) at landscape resolutions. The EMAS is evaluated and assessed with an application example in Yellowstone National Park aimed at identifying the causes and consequences of drought. Utilizing five predictor covariates (solar radiation, burn severity, soil productivity, temperature, and precipitation), spatio-temporal analysis revealed how landscape controls and climate (summer vegetation moisture stress) affected patterns of NPP according to vegetation functional type, species cover type, and successional stage. These results supported regional and national trends of NPP in relation to carbon fluxes and lag effects of climate. Overall, the EMAS provides valuable decision support for PAs regarding informed land use planning, conservation programs, vital sign monitoring, control programs (fire fuels, invasives, etc.), and restoration efforts.
\end{abstract}

(C) 2009 Elsevier Inc. All rights reserved.

\section{Introduction}

Changes in climate, atmospheric $\mathrm{CO}_{2}$ concentrations, land use/land cover, forest pathogens, and fire regimes over the past few decades have raised serious monitoring and management concerns in national parks and protected areas. In response, scientists, conservationists, and land managers have developed programs to monitor ecosystem indicators or "vital signs" that respond to environmental change (Jean et al., 2004), including remote sensing applications (Gross et al., 2006). Spatial and temporal changes in indicators presumably provide decision support, but seldom provide insight into causes (which agents) and consequences (predictions, including forecasting). Nonetheless, properly designed monitoring programs do inherently provide the experimental setting to provide such insight if natural treatments and policy experiments occur, and are measured and then analyzed.

Such monitoring programs are expensive primarily due to the size and logistical constraints of national park, designated wilderness, wildlife refuge, and other protected area (collectively hereafter, abbreviated as PA) ecosystems. However, recent deployment of

\footnotetext{
* Corresponding author. Department of Ecosystem and Conservation Sciences, College of Forestry and Conservation, University of Montana, 32 Campus Drive, Missoula, MT 59812, United States.

E-mail address: crabtree@yellowstoneresearch.org (R. Crabtree).
}

space-borne sensors (e.g., Moderate Resolution Imaging Spectroradiometer, MODIS) has systematically generated ecological indicators available at regional scales at no or low cost (Justice et al., 1998). In addition, remote sensing data, unlike traditional field plots, provide geospatial products that reveal continuous patterns in both space and time-often crucial to uncovering cause and consequence. These satellite data can now be acquired at varying spatial ( $1 \mathrm{~m}$ to $1 \mathrm{~km})$ and temporal (daily to annual) resolutions globally to track environmental impacts such as land use, disturbance, and climate change. Based on the existing literature of optimal trade-space between spectral, spatial, and temporal resolutions, remote sensing data provide great potential for monitoring indicators of environmental change and ecosystem health. Assessing the causes and consequence of these spatio-temporal patterns, however, will require new monitoring and analysis tools that ingest geospatial subsamples of PA ecosystems.

Beyond these technological breakthroughs, there still exists a large gap between science and conservation applications on-the-ground (Anonymous, 2007). As technical, computational, and modeling methodologies increase in complexity, this gap has the potential to become even wider, at a time when it needs to be bridged (Wiens, 2002). This becomes the key charge of those concerned with successful, long-term management strategies for PA's-many of which are undergoing rapid changes. Furthermore, decision-makers in increasingly complex PA settings need access to standardized, transparent, and validated methods 
for data collection regimes, data processing techniques, and predictive models. Conservation of species, and the ecosystem processes that support them, will require a more effective set of programmatic linkages that narrow the gap between the scientists (researchers and academics) who are forging ahead with new methodologies, and the end-user practitioners who require straightforward, cost-effective tools in order to make informed and defensible management decisions (Marris, 2007).

A recent effort, the National Park Service (NPS) Inventory and Monitoring program (Jean et al., 2004) provides an ideal platform for bridging the 'implementation gap', and bringing together state-ofthe-art methods with the pressing imperatives of informed management decision-making. Such decision support systems, if properly designed in partnership with practitioners, can serve a critical role by working toward the development of robust and transparent methodologies for PA monitoring, modeling and forecasting. Practitioners are often trained scientists and biologists, yet they need access to decision support tools to guide management actions and create strategies that make federal lands resilient to future environmental impacts such as climate change, invasive pathogens, and large-scale disturbances (L. Timchak, USFS (United States Forest Service) and; T. Olliff, NPS (National Park Service), pers. commun. 2007).

To bridge this gap and assess these needs, we have taken a new approach based on satellite data and ecosystem modeling. In this paper, we describe an ecosystem-scale monitoring and analysis system (EMAS) with an example application-recent drought in Yellowstone National Park (YNP) - to provide practitioners a low-cost, end-to-end framework that they can solely operate given the levels of support, training, and hardware/software resources currently available within the federal land management agencies. We assume that the ecosystem-wide, remotely sensed parameters (e.g., NPP (net primary productivity), fire fuels, LAI (leaf area index), growing season, stand biomass) are provided at no or low cost to the practitioner at landscape resolutions. Second, we assume that practitioners have access to (1) a GIS (Geographic Information System, e.g., ArcGIS), (2) a relatively fast computer with 2 GB RAM, and (3) a statistician and/or statistics package (e.g., SAS or "R") with overnight CPU run times of $8 \mathrm{~h}$ or less. We felt these were reasonable criteria to implement an EMAS that is practical, functional, and hopefully, operational.

Thus, it is the goal of this paper to empower practitioners with a decision support modeling and analysis framework applicable to a variety of ecosystem indicators. Our objectives are to: (1) describe and develop an end-to-end, low-cost, flexible EMAS for practitioners to monitor PA ecosystems using modeled NPP as an example geospatial response variable, (2) apply a generalized statistical framework for spatial and temporal analysis of ecosystem indicators to assess causes and consequences of environmental change/impacts using drought as an application example, and (3) evaluate and assess the results from the standpoint of applied science and decision support.

\section{An ecosystem-scale monitoring and analysis system (EMAS)}

In this section we describe and justify the basic framework for practitioners to understand, and gain access to, an EMAS by application to an example PA ecosystem indicator, NPP. The core of the EMAS is a generalized statistical model for geospatial data where the chosen ecosystem indicator represents a 'response' variable in relation to a set of chosen predictor variables, hereafter referred to as 'covariates'. The paper is then organized as follows: First, the extensive methods section provides a general guide for practitioners considering the use of geospatial data in a statistical model. Second, we then provide a description of: (a) the statistical approach including the spatial linear model with spatial autocorrelation, (b) the ecosystem model that estimates NPP as the response variable, and (c) the derivation of covariates that are, at least partially, under the control of practitioners (e.g., fire, soil properties) as well as those that are not (e.g., climate). Third, we provide the results and discussion of the application example: spatio-temporal analysis of the 2001-2004 drought with a specific spatial analysis of YNP during 2001.

For our EMAS application, we chose terrestrial NPP as an indicator response variable, given its attention in remote sensing applications and its stature as a measure of ecosystem health. The history of NPP science including its theoretical basis and importance is reviewed by Running et al. (2004). Terrestrial productivity is probably the most fundamental measure of ecosystem and global change due to its ability to track the carbon cycle, providing a unifying metric for desertification, deforestation, disturbances (e.g., fire and insect outbreak), impacts of pollution and climate change. NPP provides a comprehensive evaluation of ecosystem status and services including measures of changes in ecosystem health, habitat and wildlife, and ecological footprint (Running et al., 2007).

The monitoring of ecosystem-wide indicators at landscape resolutions ( $1 \mathrm{~km}$ or less) is now feasible with satellite remote sensing. Instruments like Landsat have been applied to vegetation monitoring (Curran et al., 1992; Reeves et al., 2001). The launch of NASA's Terra satellite platform in 1999, with MODIS instruments on-board, initiated a new era in vegetation monitoring. Direct input of time series satellite vegetation "greenness" data from the MODIS sensor into ecosystem simulation models can now be used to estimate spatial and temporal variability in ecosystem properties using, for example, monthly net primary production (NPP), biomass accumulation, and litter fall inputs to soil carbon pools (see Potter et al., 2003 for the NASA-CASA model). These global MODIS vegetation data sets are available at no charge from NASA data centers, which makes their application for ecosystem monitoring feasible, once proven to be scientifically robust.

\subsection{Modeled NPP as indicator response}

Practitioners may choose other ecosystem indicators including standard MODIS data products (see Justice et al., 1998). We chose, however, to demonstrate some of the advantages of an indicator derived from an ecosystem model. We chose the NASA-CASA model (Potter et al., 1993, 1999, 2003), to produce annual NPP estimates because it (1) uses 250-meter MODIS EVI inputs, which are better suited to capture spatial heterogeneity than $1 \mathrm{~km}$ MODIS inputs (standard NPP product) for this study, (2) computes a full soil water balance and plant moisture stress sub-model to regulate monthly NPP estimates, including soil freeze-thaw dynamics and snow melt contributions (Fig. 1), (3) has been extensively calibrated and validated using measured NPP from ecosystems worldwide, and (4) further computes coarse woody litter pools, soil litter decomposition, and full soil respiration fluxes of $\mathrm{CO}_{2}$. Thus, a practitioner could choose one of NASA-CASA's many output data products to analyze and further investigate PA impacts/changes.

A four year NPP time series sequence for YNP was generated from NASA-CASA at $250 \mathrm{~m}$ landscape resolution (156,716 data values per year) to examine possible effects of a drought (2001-2004) and to add an important temporal component to the EMAS for practitioners. Year 2001 was the lowest recorded annual precipitation for YNP (recorded at Mammoth Hot Springs, WY) and was chosen for the application of a spatial linear model to explain the variation in NPP across YNP. Such models are increasingly being used in ecology (Legendre, 1993; Lichstein et al., 2002). A full spatio-temporal autoregressive model was beyond the scope of practitioners' resources but see Gregoire et al. (1997) for examples. However, there are new methods available that can greatly reduce computational time and efficiency (Pace \& Barry, 1997b)) and permit analysis across time. Similar to Nemani et al. (2009-this issue), we examined temporal patterns of NPP with GIS analysis methods to assess climate and landscape controls on vegetation types in YNP. We chose to use existing YNP cover type maps-a commonly used 'functional type'-for our temporal analysis. PA ecosystems are often subdivided into mapped vegetation categories selected from the perspective of practitioners that need to understand environmental impacts and then consider management actions. 


\section{$\begin{array}{ll}\text { (a) Soil Moisture Balance } & \text { (b) Ecosystem Production }\end{array}$ and Plant Functional Types Nutrient Mineralization}

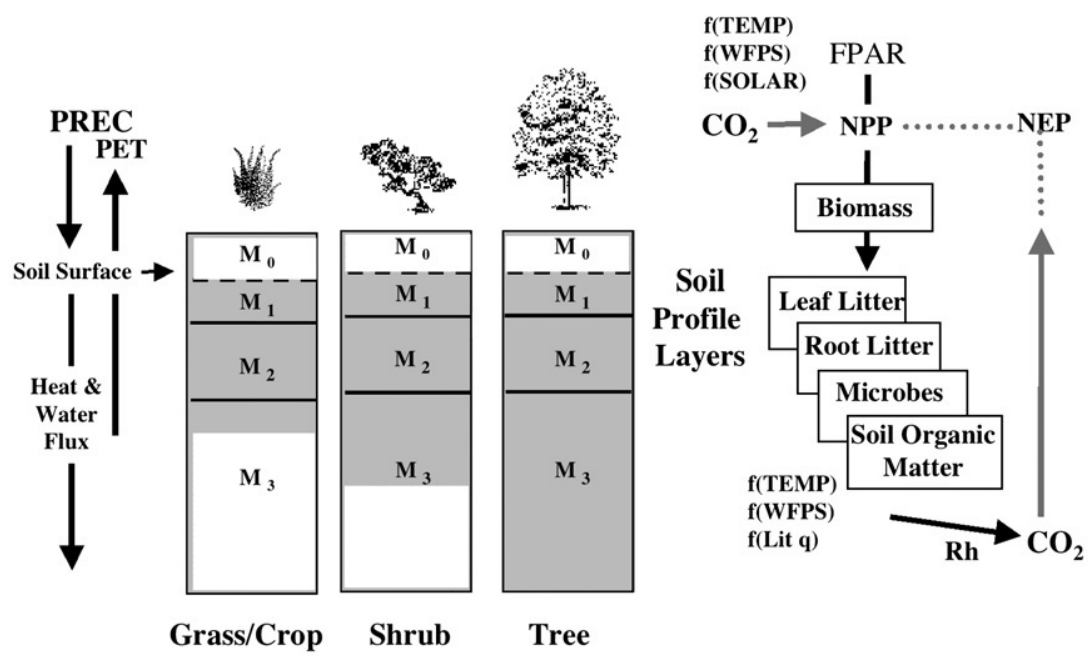

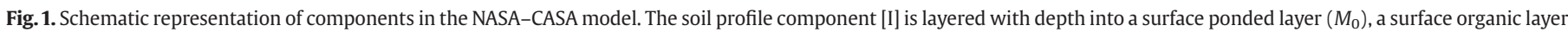

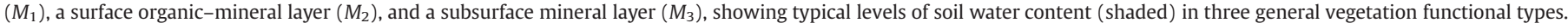

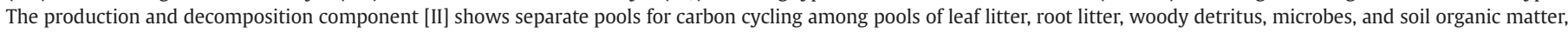
with dependence on litter quality $(q)$.

\subsection{Geospatial covariates for indicator response modeling}

Covariate selection for ecological modeling is both an art and a science (Wiens, 2002) and geospatial covariates provided by remote sensing are required for ecosystem indicator response modeling in our EMAS. As with other studies (see Heglund, 2002), we advocate selecting known causal covariates from expert knowledge (e.g., scientists, field biologists) and a priori models based on previous modeling exercises and related publications. For these reasons we chose 5 geospatial covariates for our application example: fire severity, solar radiation, soil productivity, temperature, and precipitation. Some of these covariates are used to derive the modeled estimates of NPP, albeit at different scales, and caution should be used in the interpretation of model results.

We envision that each PA will choose appropriate ecosystem indicators along with an assembled set of geospatial covariates that can explain spatial and temporal patterns or identify environmental drivers. There are some standard sets of covariates available nationwide such as National Land Cover Data (NLCD), digital elevation models, digital maps, and soil maps but they will not provide all the necessary covariates for all applications. However, recent work by Nemani et al. (2009-this issue) provides a comprehensive suite of $30+$ covariates for modeling including freeze/thaw, land cover, snow cover, surface temperature, vegetation density and productivity, surface weather station data (temperature, humidity, solar radiation, rainfall), and modeled fluxes (soil moisture, vegetation condition/ stress). Useful covariates can be also generated with methods within a simple GIS (e.g., distance to road, see Goetz et al., 2009-this issue).

\section{Methods}

The statistical modeling and analysis of geospatial data derived from GIS and remote sensing data faces significant challenges that must be addressed: (1) pixels do not necessarily represent a measured object, (2) nearby pixels are spatially dependent or autocorrelated, and (3) manipulations such as resampling techniques incur complex propagation of error. A review of these and related issues is provided by Henebry and Merchant (2002). The first issue can largely be avoided if the chosen indicator is a continuous variable such as density, percent cover, or productivity. The second issue must always be addressed when using wall-to-wall geospatial data such as remotely sensed imagery. Otherwise severe pseudoreplication will likely occur (Hurlbert, 1984), leading to erroneous model selection results and interpretations. There are numerous methods available to address this issue (Zhang et al., 2005) and we applied standard semivariogram analysis and then included a spatial correlation term in our analysis. The last issue is perennial and must be addressed with caution. If no effort is made to guard against error propagation, spurious relationships can result (Openshaw \& Alvanides, 1999) which is the geospatial equivalent to a series of Type I errors.

\subsection{Statistical response analysis using spatial linear models}

For practitioners using continuous geospatial data, spatial linear models are feasible to apply, provided that the non-independence (i.e., spatial autocorrelation) of the response variable is accounted for. More specifically, the value of NPP calculated for a given pixel can have varying amounts of (1) exogenous correlation, and (2) endogenous or neighboring correlation out to a certain distance (Fortin \& Dale, 2005). The former refers to an important ecological and landscape processes affecting the NPP which is not unrelated to the latter type. The latter refers to the direct relationship of neighbors, for example, unusually high NPP in one cell will undoubtedly spill over into neighboring cells. This type of spatial autocorrelation can be accounted for in statistical analysis methods. Again, because the issue of spatial dependence is inherent in all continuous remote sensing data products, we suggest Hunsaker et al. (2001, chapter 10) for practitioners. We use the same notation here to describe the general model used in our application example:

$Y_{i}(s)=\beta_{0}+\beta_{1} x_{i 1}(s)+\ldots+\beta_{j} x_{i j}(s)+Z_{i}(s)$

where $Y_{i}$ is the response for the $i^{\text {th }}$ variable and the vector $\mathbf{s}$ contains its location in space $x_{i j}(s)$ is the $j^{\text {th }}$ observed value of the $i^{\text {th }}$ variable (where again, the vector $\mathbf{s}$ contains its location in space), $\beta_{j}$ the coefficient for the $i^{\text {th }}$ variable and $Z_{i}(s)$ is the random error with a mean of zero and possible autocorrelation (Hunsaker, 2001). For the spatial linear model of NPP, our chosen covariates are those whose values are used in Eq. (1) as $x_{i 1} \ldots x_{i j}$, where $j=1$ to 5 . In order to solve Eq. (1), a large $i \times i$ matrix is generated where $i$ is the number of observations. 
Given the size of YNP and the guidelines in Pace and Barry (1997a,b), the NPP observations for one year would require $~ 170$ GB for estimating the variance-covariance matrix within a spatial linear model. Although there has been recent work to remedy this unwieldy problem with large geospatial data sets (Pace \& Barry, 1997a,b; Sone \& Griffith, 1995; Zimmerman, 1989), we propose an approach that largely accounts for spatial autocorrelation that can be performed on a standard desktop computer. Thus, we chose an adaptation of a linear mixed model with spatially correlated errors using SAS. An excellent reference for practitioners regarding the application of SAS to spatially dependent models (and many others) is Littell et al. (2006). All effects remain fixed, there are no random effects. We also chose $8 \mathrm{~km}^{2}$ blocks as independent groups with which to assess spatial autocorrelation. This adaptation can be reflected in Eq. (1) by adding a subscript to the error term;

$Y_{i}(s)=\beta_{0}+\beta_{1} x_{i 1}(s)+\ldots+\beta_{j} x_{i j}(s)+Z_{i k}(s)$

where $Z_{i k}$ is the error for the ith cell in the $k$ th $8 \mathrm{~km}$ block, and all other terms are the same as Eq. (1). By creating a different error term for each of the $k$ blocks, ( $k=1$ to 171$)$, the blocks are assumed independent with respect to the spatial autocorrelation between them, and the computation time is greatly reduced. Typically, users could define independent groups when plots or regions are spatially independent. For instance, if the analysis involved $8 \mathrm{~km}^{2}$ blocks that were separated geographically by $8 \mathrm{~km}$, this option allows the simultaneous analysis of both blocks using the same spatial autocorrelation term within each block but without any spatial autocorrelation between blocks. This should not be confused with a random block effect where the intercept and/or slope of the regression is allowed to differ between blocks. In our model, all of the covariates are considered fixed effects, thus they are not allowed to vary between blocks. Practitioners can double check their SAS output and note that the number of columns in the $\mathbf{Z}$ matrix is zero. This confirms that no random effects are being used. The same analysis could be performed with other software packages such as $R$, which is freely available. Users that will be attempting this or similar models in $R$ will find Bivand et al. (2008) useful.

\subsubsection{Preliminary methods for the spatial linear model}

Initial data summaries, visual inspections, univariate statistics, and correlation plots were performed on the adjusted NPP values in order to determine if some covariates should be grouped if found to be collinear. These procedures were also used to group monthly covariates into seasonal totals. Correlations indicated to combine the March through June values for precipitation, temperature, and solar radiation into a "growing season" set of covariates for the analysis. Due to the nonlinear relationship of fire and NPP, we log transformed fire which improved the linear fit of the model.

Due to the structure of the NASA-CASA (Carnegie-Ames-Stanford) model, some distinct systematic effects occurred at regular $8 \times 8 \mathrm{~km}$ blocks, especially around Yellowstone Lake. Systematic anomalies are not uncommon in geospatial modeling with data sets of differing resolutions and some occurred due to the downscaling of timevarying climate data. Thus, we standardized across YNP by subtracting a block's correction value from each block's NPP value. The correction value was simply the difference between the overall mean and the block mean. NPP values near Yellowstone Lake were removed from the analysis due to the large fraction of water within those blocks and no inferences were made with regard to the shoreline blocks.

\subsubsection{Spatial autocorrelation and model selection}

Since blocks were sufficiently large, empirical variograms were individually constructed for each of the $171\left(8 \mathrm{~km}^{2}\right)$ blocks throughout the park and inspected for spatial autocorrelation. Based on the observed values for range in a large majority of the variograms, we fixed the range value at $1500 \mathrm{~m}$ for all $8 \times 8 \mathrm{~km}$ blocks in the model and assumed all blocks were independent. While topography resulted in some differences in the variograms, fixing the distance to $1500 \mathrm{~m}$ greatly reduced the computation time from over $6 \mathrm{~h}$ down to about $90 \mathrm{~min}$. Likewise, treating each $8 \mathrm{~km}^{2}$ block as independent allowed for a reasonable computation time for each model. To address the spatial dependence across boundaries, a moving window approach was considered, but that greatly increased the computation time needed for model selection. After the full model was run, standard regression diagnostics were performed and resulted in the need to log transform the NPP values. As with any regression, extremely high values for a covariate can lead to correlation with the intercept. This can be eliminated by scaling the covariate and/or centering the covariate on zero. For this reason, solar radiation values were scaled and centered on zero.

The full model with all 5 covariates was then rerun, with 5 subsequent runs that left out one different covariate each time. In no case did the removal of a covariate lead to a more parsimonious model, therefore all covariates were included. Standard information theoretic model selection criteria were applied (Burnham \& Anderson, 2002) and we chose Bayesian Information Criteria (BIC) (Schwarz, 1978) because Akaike Information Criteria (AIC) tends to overfit with very large data sets. All models were fit using maximum likelihood estimation procedures. Model selection was carried out in a series of model run times of one-half to $2 \mathrm{~h}$.

\subsection{The NASA-CASA model for NPP}

We herein describe the model used to generate the NPP indicator response data. As documented in Potter et al. (1993, 1999, 2003), monthly NPP flux, defined as net fixation of $\mathrm{CO}_{2}$ by vegetation, is computed in NASA-CASA on the basis of light-use efficiency (Monteith, 1972). Monthly production of plant biomass is estimated as a product of time-varying surface solar irradiance (Kistler et al., 2001), Sr, and EVI from the MODIS satellite (Huete et al., 2002), plus a constant light utilization efficiency term $\left(e_{\max }\right)$ that is modified by time-varying stress scalar terms for temperature $(T)$ and moisture $(W)$ effects (Eq. (1)).

$\mathrm{NPP}=S_{r}$ EVI $e_{\max } T W$

The $T$ stress scalar is computed with reference to derivation of optimal temperatures ( $T_{\text {opt }}$ ) for plant production (Potter, 1999). The $T_{\text {opt }}$ setting will vary by latitude and longitude, ranging from near $0{ }^{\circ} \mathrm{C}$ in alpine zones to the middle thirties in desert zones. The $W$ stress scalar is estimated from monthly water deficits, based on a comparison of moisture supply (precipitation and stored soil water) to potential evapotranspiration (PET) demand using the method of Priestly and Taylor (1972). Water balance in the soil (Fig. 1) is modeled as the difference between precipitation or volumetric percolation inputs, monthly estimates of PET, and the drainage output for each soil layer. Inputs from rainfall can recharge the soil layers to field capacity. Excess water percolates through to lower layers and may eventually leave the system as seepage and runoff. Freeze-thaw dynamics with soil depth operate according to the empirical degreeday accumulation method (Jumikis, 1996, as described by Bonan, 1989).

The CASA model $e_{\max }$ term is set uniformly at $0.55 \mathrm{~g} \mathrm{C} \mathrm{MJ}^{-1} \mathrm{PAR}$, a value that derives from calibration of predicted annual NPP to previous field estimates (Potter et al., 2007b). This model calibration has been validated globally by comparing predicted annual NPP to more than 1900 field measurements of NPP (Olson et al., 1997; Zheng et al., 2003). Inter-annual NPP fluxes from the CASA model have been validated against multi-year estimates of NPP from field station data in numerous studies (Amthor et al., 2001; Hicke et al., 2002; Lobell et al., 2002; Potter et al., 2001; Potter et al., 2007a) and from tree ring studies (Malmström et al., 1997). 


\subsection{Generation of predictor covariates}

We chose 5 geospatial covariates for NPP response modeling: fire severity, solar radiation, soil productivity, temperature, and precipitation. These were selected as demonstrated predictors of NPP, and are grounded in the literature (see Waring \& Schlesinger, 1985, for review). Temperature and precipitation, two of $30+$ ecological variables available from TOPS (Nemani et al., 2009-this issue), were obtained from PRISM (Daly, 2006).

\subsubsection{Fire severity}

Fire severity is defined as the degree of environmental or ecological change caused by a wildfire event (Jakubauskas et al., 1990; Key \& Benson, 2005; Tanaka et al., 1993; White et al., 1996). Various methods can be used to estimate burn severity including field measurement and remote sensing. The primary parameters measured in burn severity assessment are vegetation loss, regeneration, scorching, consumption and the effect on soil condition (Jakubauskas et al., 1990; Key \& Benson, 2005). As a covariate in our NPP response model we used a remotely sensed burn severity index called Differenced Normalized Burn Ratio (dNBR). This burn severity index is generated from Normalized Burn Ratio (NBR), the difference of near infrared (NIR) and middle-infrared (MIR) reflectance divided by the sum, defined as:

$\mathrm{NBR}=(\mathrm{NIR}-\mathrm{MIR}) /(\mathrm{NIR}+\mathrm{MIR})$.

dNBR is the multi-temporal difference of pre- and post-fire NBR, defined as:

$d \mathrm{NBR}=$ NBRprefire - NBRpostfire,

which is effective at detecting the degree of change or contrast in vegetational greenness to blacking due to scorching caused by fire (Key \& Benson, 2005; Roy et al., 2006).

We acquired processed dNBR scenes for every fire year in YNP between 1988 and 2006 from the joint National Park Service (NPS) and U.S. Geological Survey (USGS) National Burn Severity Mapping Project (http://burnseverity.cr.usgs.gov/firemain.asp). The NPSUSGS product is a $30 \mathrm{~m}$ dNBR derived from Landsat TM, which utilizes band 4 (NIR) and band 7 (MIR) to derive NBR and dNBR through Eqs. (1) and (2). The NPS-USGS dNBR scenes were then masked to the associated fire perimeter and temporally mosaiced to one image. By temporally mosaicing these images we ensured the most recent fire values for areas with multiple burns between 1988 and 2001. Finally, to capture, and standardize, the effect of fire severity on NPP, we divided all fire values by the number of years since the fire.

\subsubsection{Soil productivity}

The soil productivity values created for this analysis are 15 groups of increasing soil productivity based on information contained within Rodman et al. (1996) for soil types within YNP. The 79 map units described in the report delineate groups of different soils that occur together in repeating patterns on the landscape. Major soil properties were grouped to maximize differences between units and minimize differences within units. The 85 different soils described within the report are based on more than 1100 soil profiles whose locations were chosen to represent the range of important features that influence soil development across YNP. Soil included soil texture, organic matter, depth of a dark A horizon, cation exchange capacity, base saturation, $\mathrm{pH}$, percent (by volume) of large rock fragments, and presence of root-limiting layers. The percent of the map unit covered by bedrock or talus slopes rather than soil was also taken into consideration. Groupings are as follows:

Group 1 - dominated by large areas of bedrock or talus slopes and without adequate soil to support substantial vegetation.
Group 2 - dominated by soils similar to Groups 10 to 13 but also containing a significant percent (10-15\%) of soils influenced by acid, hydrothermal activity.

Groups 3, 4, 5, 6 - dominated by soils with thin, light colored surface horizons, coarse textures, a large volume of rock fragments and low base saturation.

Group 7 - a mix of soils with thin surface horizons and high clay content. High clay soil fraction augments water holding capacity, but too much acts to limit water availability to plants.

Group 8 -a mixture of thin and thick surface horizons unlike Groups 6 and 7. Those with thick, dark surfaces tend to be dominated by soils with lower base saturations. Lower base saturation, in general, indicates lower fertility.

Groups 9, 10 - a mixture of productive and nonproductive soils with nonproductive soils characterized by thin surface horizons and coarse textures.

Group 11 - soils with thick, dark surface horizons and loamy textures dominate, but bedrock can make up from $20 \%$ to $60 \%$ of the map unit.

Groups 12, 13 - still dominated (43-80\%) by soils with dark surface horizons, but these map units include more soils with thin surface horizons. Textures of these soils tend to be sandier and bedrock takes up a larger percentage (3-20\%) of the map unit. Group 14, 15 - dominated (80-100\%) by soils that have dark (high organic matter) and deep $(30-80 \mathrm{~cm})$ surface horizons. There are no root-limiting layers and textures are generally loamy.

\subsubsection{Solar radiation}

Solar radiation is modified as it travels through the atmosphere, is further modified by topography and surface features, and is intercepted at the earth's surface as direct, diffuse, and reflected components available for plant photosynthesis. We used the solar radiation tool contained in ArcGIS 9.2 Spatial Analyst, which is based on the hemispherical viewshed algorithm developed by Fu and Rich (2002), to calculate the monthly solar radiation in YNP. This calculation was based on topography and observed variation in atmospheric conditions, accounting for site latitude, elevation, surface orientation (slope and aspect), daily and seasonal shifts in sun angle, and effects of shadows cast by surrounding topography. The details of the model were described in Huang et al. (2008). The solar radiation model resulted in the geospatial covariate for model input at 30 meter postings. For conversion to 250 meter postings we averaged all 30 meter postings.

\subsubsection{Temperature and precipitation}

Monthly mean maximum temperature and monthly precipitation used in this model were $4 \mathrm{~km}$ PRISM data (PRISM Group, Oregon State University, http://www.prismclimate.org, created August 2004). The values are interpolated from monitoring stations using a regression model to account for elevation, as well as moisture index, effective terrain height, topographic facets, inversions, and cold air drainages to account for local weather changes. The PRISM model is well suited for mountainous terrain (Daly, 2006) such as that found in YNP. For both precipitation and temperature, the $4 \mathrm{~km}$ resolution required using data in the model in neighboring grids (blocks of 256). There are finer resolution data sets available, but finer scale does not mean a model that is more accurate to the true conditions (Daly, 2006). The data are freely available and can be downloaded from the Internet in monthly or yearly averages. These climate data are projected using a combination of four projections, so care must be taken when re-projecting them to another format.

\subsubsection{Temporal GIS analysis of modeling results}

We used the general procedures of Nemani et al. (2009-this issue) to assess the effects of climate on temporal patterns in NPP during 

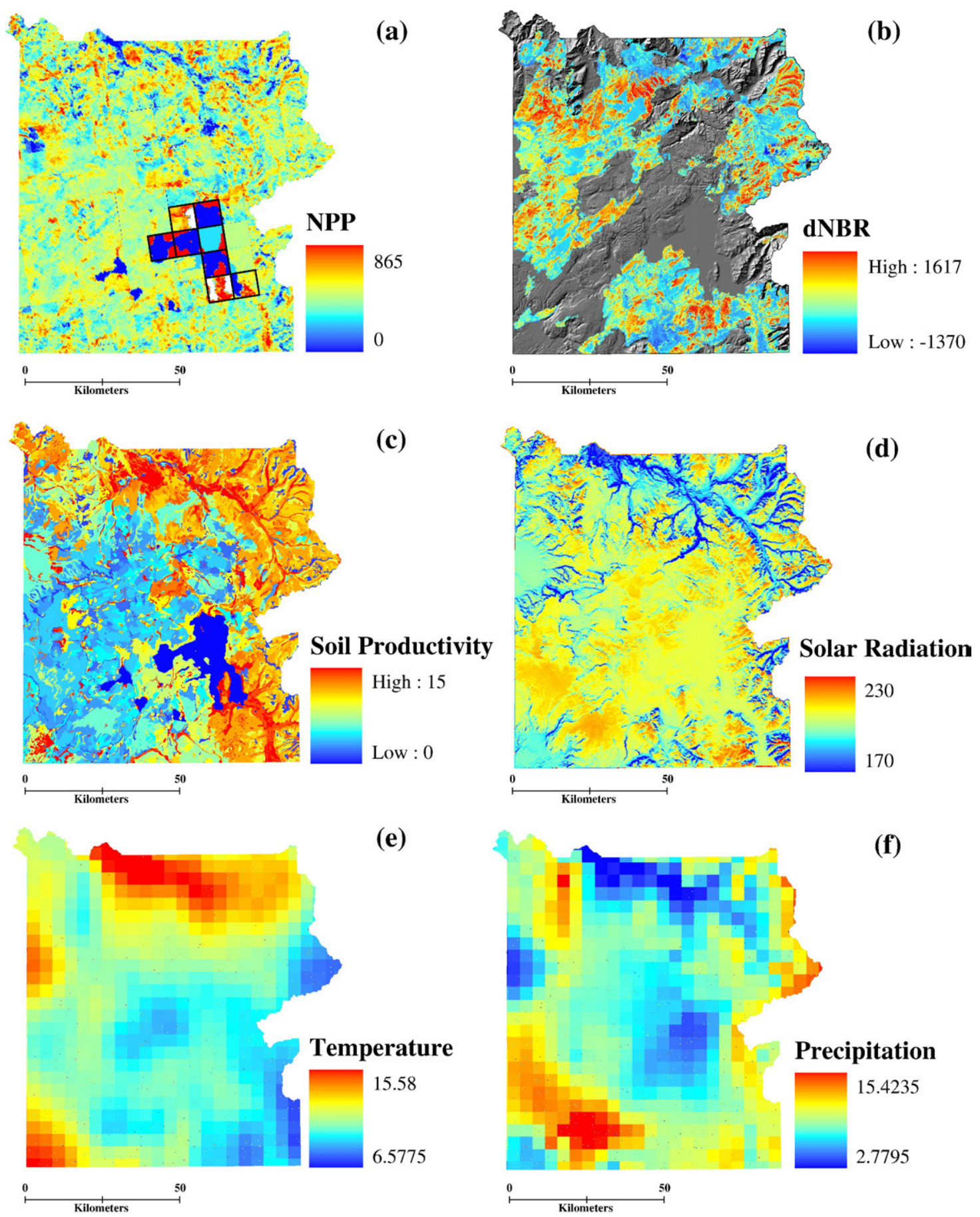

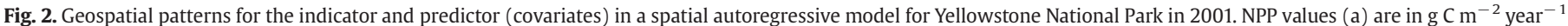

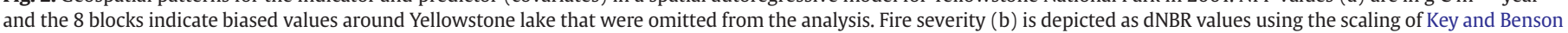

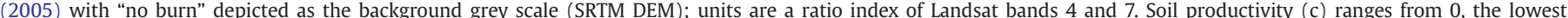

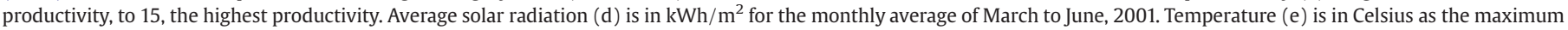
daily temperature averaged for March to June. Precipitation (f) is in centimeters as the average of monthly rainfall from March to June.

drought (2001-2004). Relative to precipitation and temperature, fire severity, soil productivity, and solar radiation are assumed constant during this period. Geospatial anomalies are generated by subtracting the NPP values of each year from the time series mean values.

Given the above spatial and temporal analysis methods, we then sought to further examine spatio-temporal variation in NPP by using GIS analysis to examine within and between year patterns of NPP with regard to vegetation functional type and forest successional stage. We used Despain (1990) habitat and cover types provided by YNP's Spatial Analysis Center. This allowed us to assess the causes and possible consequences of landscape and climate controls on productivity during drought.

\section{Results and discussion}

To further describe and demonstrate the EMAS, the results provided below are discussed with primary reference to an application example: a short time series of geospatial NPP data during a drought to assess the cause and consequences of environmental change. 


\subsection{Accounting for NPP geospatial variation with predictor covariates}

The pattern of NPP over YNP in 2001 indicates substantial landscape heterogeneity (Fig. 2a) resulting from a variety of biotic and abiotic factors. Spatial patterns of the 5 covariates were equally heterogeneous and patchy (Fig. $1 \mathrm{~b}$ to $\mathrm{f}$ ) reflecting response to landscape controls such as topography and elevation (see also Lynch et al., 2006 for fire controls). Covariates were largely independent of one another except for an expected negative relationship between temperature and precipitation $\left(r^{2}=-0.48\right.$; Fig. 2e vs. f). The summary of model results (Tables 1 and 2 ) indicate that the spatial linear model explains the spatial patterning of NPP over YNP. The full model was selected as the best fitting model (smaller BIC means better fit).

Determining the relative importance of covariates in accounting for variability in NPP is difficult with information theoretic approaches. Without model averaging (Burnham \& Anderson, 2002), which is very cumbersome given the lengthy model run times we experienced, there is no good analogy to the partial correlation coefficient which was historically used as a measure of strength of the linear relationship between the response variable and predictor covariate(s). However, the full and best model being the same is atypical and suggests we chose appropriate covariates with strong predictive capability-all five covariates have consistently been singled out as factors controlling terrestrial productivity (see Chapin et al., 2002; Waring \& Schlesinger, 1985).

We thus chose two criteria for the assessment of each covariate and their relative importance in accounting for variability in NPP across YNP: (1) which covariate when removed from the full model yielded the largest increase in BIC ( $\triangle$ BIC score in Table 1$)$, and (2) which covariates' coefficients (that do not contain zero in their $95 \% \mathrm{CI}$, see LCL and UCL, Table 2) have the smallest coefficient of variation (CV in Table 2).

The strongest influence on the spatial distribution of NPP was soil productivity $(\triangle \mathrm{BIC}=1319.5, \mathrm{CV}=0.03)$, followed by solar radiation, $(\triangle \mathrm{BIC}=227.2, \mathrm{CV}=0.07)$. Although both strongly control NPP, this indicates the importance of soil properties during drought in the semi-arid YNP. Turner et al. (2004) reported that $80 \%$ of the variation in plot-based aboveground productivity and leaf area index (LAI) in post-fire lodgepole pine stands measured across YNP was explained by sapling density and the abiotic factors, elevation and soil class. The diverse topographic variation in YNP with large amounts of shadeintolerant lodgepole pine (Pinus contorta), ensures that NPP will respond to solar radiation.

The next strongest influence on NPP was precipitation $(\triangle \mathrm{BIC}=$ $40.7, C V=0.15)$. However, precipitation and temperature $(\triangle \mathrm{BIC}=3.9$, $\mathrm{CV}=0.33$ ) were correlated and collectively represent the influence of climate in the model. We suspect the low climate signal was due to general drought conditions-the observed gradients in temperature and precipitation (Fig. 2e and f) have less effect on NPP than either soil productivity or solar radiation.

The influence of fire on NPP in 2001 is assessed by a 'fire influence index' calculated as the burn severity index divided by the number of

\section{Table 1}

Bayesian information criteria (BIC) values for the full model and each reduced model in increasing order of importance.

\begin{tabular}{llr}
\hline Model & BIC & $\Delta$ BIC \\
\hline Full model & -17323.2 & 0 \\
Soil solar precip fire (no temp) & -17319.3 & 3.9 \\
Soil solar precip temp (no fire) & -17308.6 & 14.6 \\
Soil solar fire temp (no Precip) & -17282.5 & 40.7 \\
Soil precip fire temp (no solar) & -17096.0 & 227.2 \\
Solar precip fire temp (no soil) & -16003.7 & 1319.5 \\
\hline
\end{tabular}

For model fit, smaller values are better, thus the full model is considered the best fitting, or most parsimonious model of all models that were run. Delta BIC values are a relative indication of fit compared to the most parsimonious model.
Table 2

Coefficients for each fixed effect and their related standard error.

\begin{tabular}{lrlrrl}
\hline Effect & Estimate & Error & \multicolumn{1}{l}{ LCL } & \multicolumn{1}{l}{ UCL } & \multicolumn{1}{l}{ CV } \\
\hline Intercept & 5.9347 & 0.05899 & 5.81908 & 6.05032 & 0.009940 \\
Soil & 0.01486 & 0.00041 & 0.01406 & 0.01566 & 0.027591 \\
Solar & 0.06743 & 0.00442 & 0.05877 & 0.07609 & 0.065549 \\
Precipitation & 0.02183 & 0.00322 & 0.01552 & 0.02814 & 0.147503 \\
Fire & -0.00340 & 0.00076 & -0.00490 & -0.00190 & 0.223529 \\
Temp & 0.00388 & 0.00129 & 0.00135 & 0.00641 & 0.332474 \\
\hline
\end{tabular}

All covariates are positively correlated with the exception of fire. 95\% confidence limits are shown indicating that no slope interval contains zero. Coefficient of variation (CV) is shown as an indication of the quality of the estimate (smaller is better). Note: LCL and UCL are lower and upper confidence limits, respectively.

years since the fire. Thus, areas subjected to burns of equivalent severity will differ depending on time since burn, with older burns yielding smaller values. A large proportion of YNP burned in 1988 (Fig. 2b) and accounted for $>90 \%$ of the burn area in our model. It is striking that the influence of fire severity $(\triangle B I C=14.6, C V=0.22)$ thirteen years later was similar to that of climate across YNP. Fire was recently found to be the dominant driver of the carbon balance in the central Canadian boreal forest (Bond-Lamberty et al., 2007). These investigators also found that precipitation exerted a stronger influence than temperature.

\subsection{GIS temporal analysis of NPP and climate drivers}

NPP patterns across YNP from 2001 to 2004 (Fig. 3) decreased during the drought to lows in 2002 and 2003 with a sharp increase in 2004. The corresponding climate data (Table 3 ) indicate possible lag effects of climate on NPP. Although seasonal measures of precipitation varied, 2001 was the driest year on record in YNP, yet NPP was lowest in 2003. The decrease in NPP during 2002 and 2003 is consistent with Potter et al. (1999), who attributed temporal variation in NPP to a 1 year lag effect for temperature or solar radiation and primarily, a 2 year lag for the combined drying effect of precipitation and temperature (i.e., summer moisture stress). However, the sharp rebound in NPP in 2004 indicates a more immediate vegetation response based on a within-year doubling of growing season precipitation from the previous year, and a possible 1 year lag effect of increased snowfall. The relationship between temporal variation in NPP and climate lags can be further investigated with simple multiple regression and we would advocate this, but with longer time series.

\subsection{GIS analysis of functional type and disturbance controls on NPP}

NPP varied substantially by vegetation functional type and is the result of many abiotic and biotic factors including species adaptations to widely varying (1) harsh winter climates (2) soil moisture regimes and (3) elevation and topography. These adaptations were reflected in the NPP values, and in decreasing order were: aspen (Populus tremuloides), riparian, fir and sagebrush (tied), grassland, and pine (Fig. 4a). They generally compare to the productivity rankings of Hansen et al. (2000), except for a reversal in order for aspen vs. fir, and pine had higher productivity than sagebrush and grasslands (tied). These differences are likely due to higher productivity in their lower elevation plot sites as well as a lack of drought during their study.

Between-year differences among cover types (see slope changes, Fig. 4a) were very similar (parallel) except for: (1) steeper decreases in NPP for both whitebark pine (Pinus albicaulis) classes during the worst year (2003) which indicates possible drought stress, and (2) little or no decrease in NPP for both lodgepole pine classes during the worst two years (2002 and 2003). The lack of response in lodgepole to drought stress was due to the late successional (mature) lodgepole class, and primarily the early (post-1988 fire disturbance) class (Fig. 4b). 

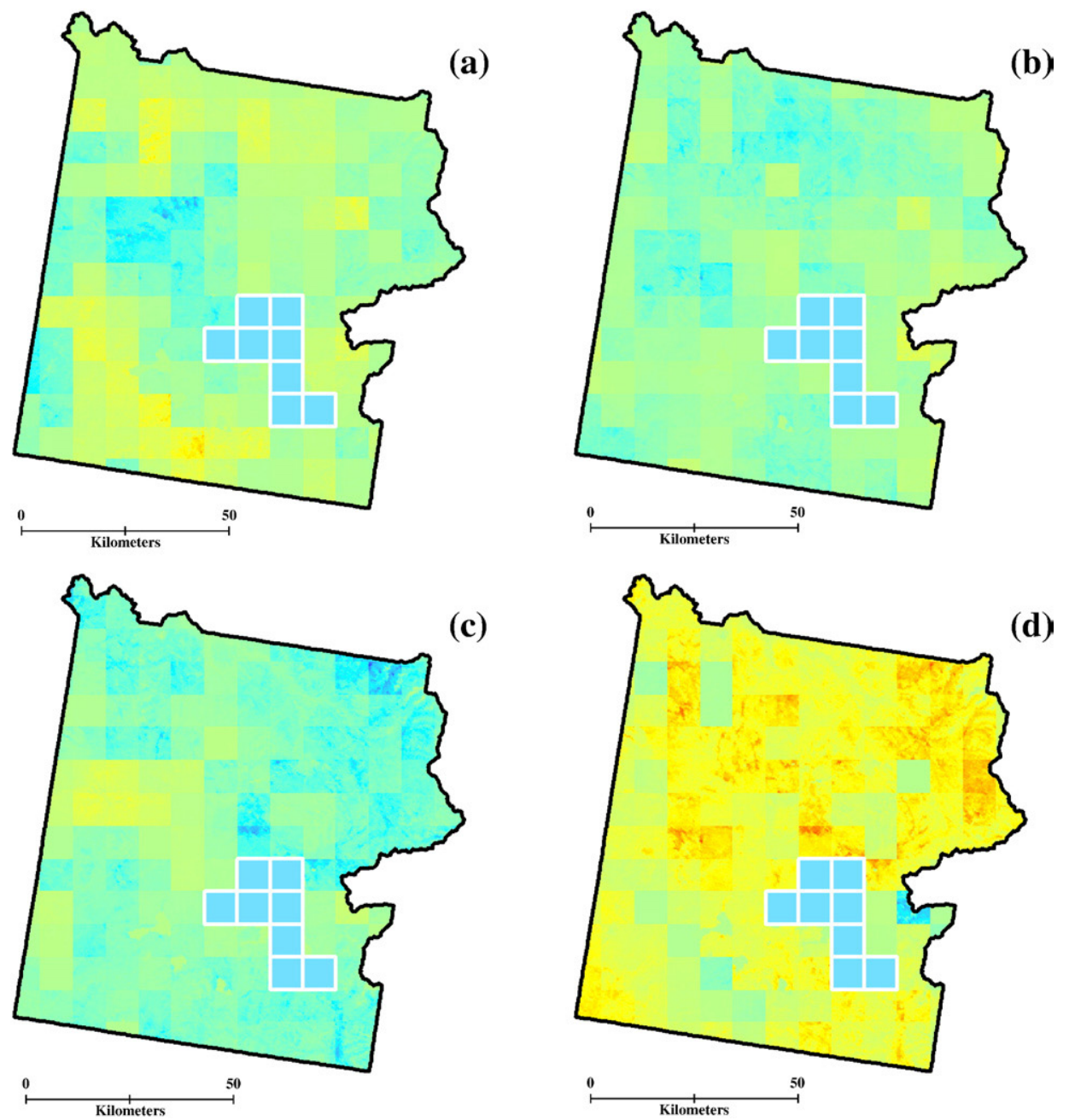

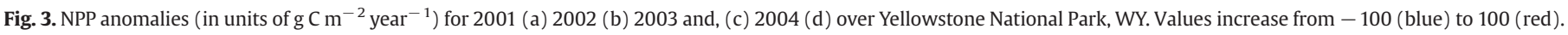
The white rectangles covering Yellowstone Lake were left due to uncorrectable bias associated with water.

NPP increases with successional stage of lodgepole pine (Fig. 4b), the most common cover type in YNP, but drops back down in the mature/climax stage to the post-disturbance levels of NPP (13 year old age class). As stand age increases (proxy to canopy closure and maximum bole diameters), mature lodgepole pine cover types may experience relatively higher autotrophic respiration rates during the growing season, compared to younger age stands characterized by smaller bole diameters and lower metabolic baselines (Ryan et al., 1997). The successional pattern of NPP in lodgepole pine, as well as the negative correlation between fire index and NPP in the spatial autocorrelation model, supports the hypothesis that an area subjected to a burn will have reduced NPP in the short-term, then slowly recover to pre-burn NPP levels, followed by a gradual decrease in NPP during later successional stages.

\subsection{Applicability of the EMAS to PA monitoring}

We used NPP analysis during a drought as an application example of the EMAS for practitioners. The results of our spatial autoregressive model account for the differential spatial patterning over YNP. The temporal analysis indicates how different vegetation functional types responded to climate change (precipitation and temperature) during a drought. Together the spatio-temporal analysis revealed likely drivers of vegetation response. Declines in NDVI or "greening" have been reported over many North American PAs including the YNP region (Goetz et al., 2006; Nemani et al., 2009-this issue) during the same period. Thus, the recent drought in YNP from 2001 to 2004 combined with continental warming since the 1970s (IPCC AR4 report 2007) and accelerated warming since 2000 (Nemani et al., 2009-this issue) has led to summer moisture stress for natural vegetation in YNP.

Our results in YNP were similar to Potter et al. (2007b) who reported carbon fluxes and NPP patterns using the NASA-CASA model across the coterminous U.S. They concluded that the year 2002 stood out from the other years within 2000 to 2004 with relatively large carbon source fluxes in ecosystems of the north eastern and north central regions of the coterminous U.S., as well as in parts of the Rocky Mountain and southern

Table 3

Total net primary productivity and seasonal climate data for Yellowstone National Park, WY.

\begin{tabular}{llllll}
\hline $\begin{array}{l}\text { NPP total } \\
\text { in YNP } \\
\left(\mathrm{g} \mathrm{C} \mathrm{year}^{-1}\right)\end{array}$ & $\begin{array}{l}\text { NPP mean } \\
\text { in YNP } \\
\left(\mathrm{g} \mathrm{C} \mathrm{m}^{-2}\right. \\
\left.\text { year }^{-1}\right)\end{array}$ & $\begin{array}{l}\text { March-July } \\
\text { average } \\
\text { temperature } \\
\left({ }^{\circ} \mathrm{C}\right)\end{array}$ & $\begin{array}{l}\text { Last October- } \\
\text { March snow fall } \\
\text { total } \\
(\mathrm{cm})\end{array}$ & $\begin{array}{l}\text { May-July } \\
\text { precipitation } \\
\text { total } \\
(\mathrm{cm})\end{array}$ \\
\hline 2001 & $34,947,668$ & 223 & 9.08 & 99.06 & 11.3 \\
2002 & $34,007,372$ & 217 & 7.35 & 140.21 & 10.4 \\
2003 & $33,380,508$ & 213 & 8.88 & 164.85 & 8.8 \\
2004 & $38,865,568$ & 248 & 8.82 & 101.35 & 16.1 \\
\hline
\end{tabular}

Note: Data are from weather station Yellowstone Park, Wyoming (Latitude $44^{\circ} 58^{\prime}$, Longitude $110^{\circ} 42^{\prime}$ ) 
(a)

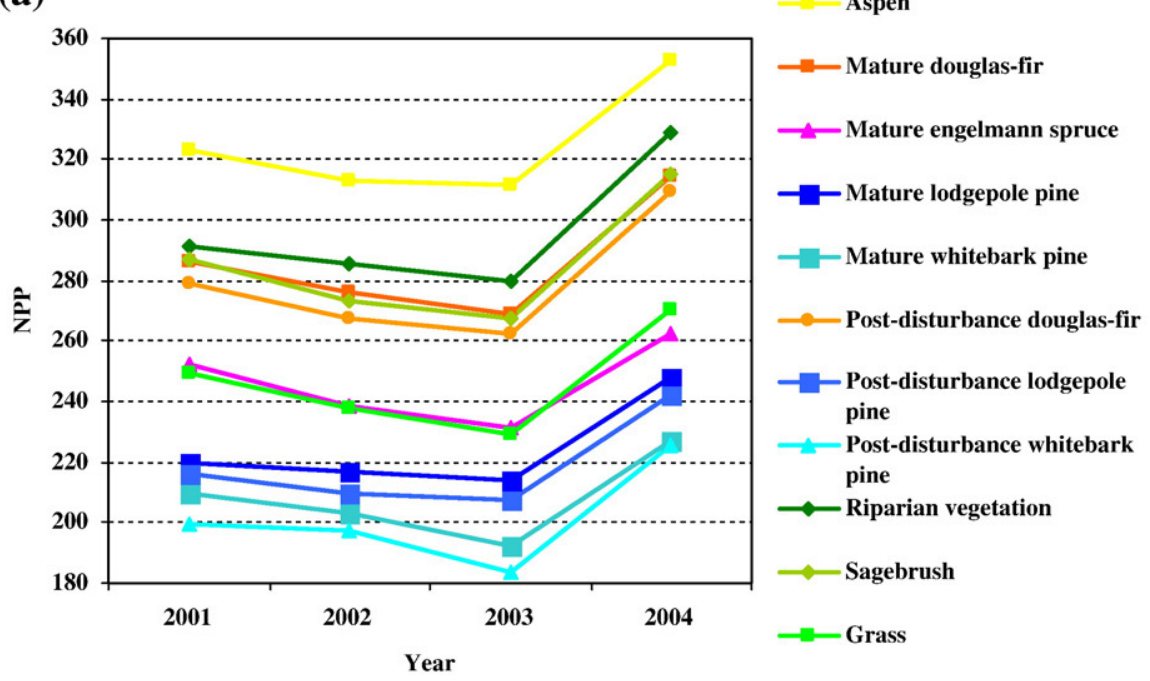

(b)

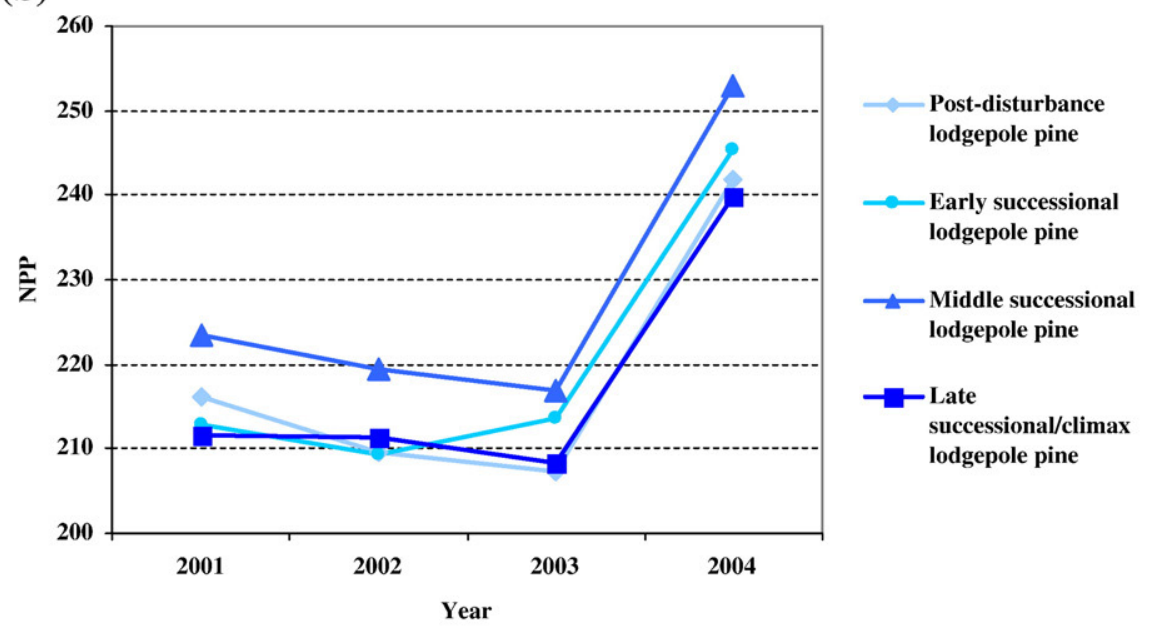

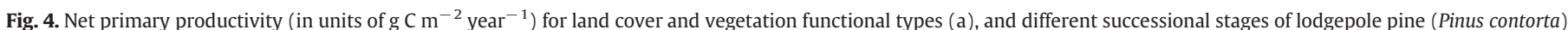
(b) in Yellowstone National Park, WY.

U.S. regions. Temperatures in the spring of 2002 were near normal nationally, compensating partially for a cooler than average March and May. Low precipitation in the U.S. in 2002 resulted in extreme dryness in the western and central U.S. Colorado had its driest year on record during 2002 and Wyoming, Nevada and Nebraska their third driest year. In contrast, annual mean temperatures were above average in 2003 and 2004 in the western U.S. regions, and below average in 2003 in the eastern U.S. regions. Precipitation in the U.S. was slightly above average in 2003 and 2004, with exceptions in the western and central U.S. regions in 2003 (where moderate to extreme drought covered more than $50 \%$ of 11 western states) and continuing into the northern Rocky Mountain and Pacific Northwest regions in 2004 (NCDC, 2004). These regional climate patterns were reflected in the predicted annual ecosystem fluxes of carbon $\left(\right.$ as $\mathrm{CO}_{2}$ ) from the NASA-CASA model, which showed extensive carbon sinks in ecosystem of the southern and eastern regions in 2003 to 2004, and major carbon source fluxes from ecosystems in the Rocky Mountain and Pacific Northwest regions in 2003 to 2004.

The application example demonstrates the utility of the EMAS for monitoring PAs using NPP as an ecosystem indicator. It allows practitioners a low-cost, end-to-end framework for rigorous analysis and evaluation of landscape level environmental drivers. Our geospatial analysis procedures also provide a toolset to move beyond descriptions of indicator patterns (see Hansen et al., 2000 for NPP) by addressing ecological questions aimed at the causes and consequences of environmental impacts such as drought. For example, a practitioner might be alerted to the fact that drought could severely impact the highly productive soils in the biodiversity-rich riparian-floodplain habitats of the semi-arid YNP ecosystem. In addition, whitebark pine stood out as a potentially distressed vegetation type and is important to a variety of species (Tomback et al., 2001).

However, for an EMAS to be successfully implemented in PA ecosystems, practitioners need to designate sites not only for validation but to assess the impacts of environmental drivers, such as differential tree growth, fire and insect outbreaks, invasive spread, large vertebrate winter-kill, reduced stream flow, and other ecosystem properties that match those predicted. We also advocate the use of simultaneous ecosystem indicators or 'vital signs' that are derived from remote sensing data (Nemani et al., 2009-this issue).

Climate is largely out of the control of practitioners with regard to land management decisions. However, fire suppression, fuel reduction programs, soil conservation practices, human land use activities, vegetation restoration programs, and management of large herbivores are not. They are all factors that influence PA indicators of ecosystem health such as NPP. 


\section{References}

Amthor, J. S., Chen, J. M., Clein, J. S., Frolking, S. E., Goulden, M. L., Grant, R. F., et al. (2001). Boreal forest $\mathrm{CO}_{2}$ exchange and evapotranspiration predicted by nine ecosystem process models: Inter-model comparisons and relations to field measurements. Journal of Geophysical Research, 106, 33, 623-33, 648.

Anonymous (2007). The great divide: the gap between theory and practice remains surprisingly wide in conservation biology (editorial). Nature, 450, 136.

Bivand, R. S., Pebesma, E. J., Gomez-Rubio, V. (2008). Applied Spatial Data Analysis with R (Use R). New York, NY. Springer Science+Business Media, LLC.

Bonan, G. B. (1989). A computer model of the solar radiation, soil moisture and soil thermal regimes in boreal forests. Ecological Modeling, 45, 275-306.

Bond-Lamberty, B., Peckham, S. D., Ahl, D. E., \& Gower, S. T. (2007). Fire as the dominant driver of central Canadian boreal forest carbon balance. Nature, 450, 89-91.

Burnham, K. P., \& Anderson, D. R. (2002). Model selection and multimodel inference, (second edition) New York: Springer.

Chapin, F. S., III, Matson, P. A., \& Mooney, H. A. (2002). Principles of Terrestrial Ecosystem Ecology. New York: Springer-Verlag.

Curran, P. J., Dungan, J. L., Macler, B. A., Plummer, S. E., \& Peterson, D. L. (1992) Reflectance spectroscopy of fresh whole leaves for the estimation of chemica concentration. Remote Sensing of Environment, 39, 153-166.

Daly, C. (2006). Guidelines for assessing the suitability of spatial climate data sets. International Journal of Climatology, 26, 707-721.

Despain, D. G. (1990). Yellowstone vegetation: Consequences of environment and history in a natural setting. Boulder, Colorado: Roberts Rhinehart.

Fortin, M. -J., \& Dale, M. (2005). Spatial analysis. Cambridge, England: Cambridge University Press.

Fu, P., \& Rich, P. M. (2002). A geometric solar radiation model with applications in agriculture and forestry. Computers and Electronics in Agriculture, 37, 25-35.

Goetz, S., Bunn, A. G., Fiske, G. J., \& Houghton, R. A. (2006). Satellite-observed photosynthetic trends across boreal North America associated with climate and fire disturbance. Proceedings of the National Academy of Sciences of the United States of America, 102, 13521-13525.

Goetz, S., Jantz, P., \& Jantz, C. A. (2009). Connectivity of core habitat in the northeastern United States: Parks and protected areas in a landscape context.Remote Sensing of Environment, 113, 1421-1429 (this issue).

Gregoire, T. G., Brillinger, D. R., \& Diggle, P. J. (1997). Modelling longitudinal and spatially correlated data. New York: Springer-Verlag.

Gross, J., Nemani, R., Turner, W., \& Melton, F. (2006). Remote sensing of national parks. Park Science, 18, 299-305.

Hansen, A. J., Rotella, J. J., Kraska, M. P. V., \& Brown, D. (2000). Spatial patterns of primary productivity in the Greater Yellowstone Ecosystem. Landscape Ecology, 15, 505-522.

Heglund, P. J. (2002). Foundations of species-environment relations. In J. M. Scott, P. J. Heglund, F. Samson, J. Haufler, M. Morrison, M. Raphael, \& B. Wall (Eds.), Predicting species occurrences: Issues of accuracy and scale (pp. 35-41). Covelo, California: Island Press.

Henebry, G. M., \& Merchant, J. W. (2002). Geospatial data in time: Limits and prospects for predicting species occurrences. In J. M. Scott, P. J. Heglund, F. Samson, J. Haufler M. Morrison, M. Raphael, \& B. Wall (Eds.), Predicting species occurrences: Issues of accuracy and scale (pp. 291-313). Covelo, California: Island Press.

Hicke, J. A., Asner, G. P., Randerson, J. T., Tucker, C. J., Los, S. O., Birdsey, R., et al. (2002) Satellite-derived increases in net primary productivity across North America, 19821998. Geophysical Research Letters, 29, 1427. doi:10.1029/2001GL013578.

Huang, S., Rich, P. M., Crabtree, R. L., Potter, C. S., \& Fu, P. (2008). Modeling monthly nearsurface air temperature from solar radiation and lapse rate: Application over complex terrain in Yellowstone National Park. Physical Geography, 29(2), 158-178.

Huete, A., Didan, K., Miura, T., Rodriguez, E. P., Gao, X., \& Ferreira, L. G. (2002). Overview of the radiometric and biophysical performance of the MODIS vegetation indices. Remote Sensing of Environment, 83, 195-213.

Hunsaker, C. T., Goodchild, M. F., Friedl, M. A., \& Case, T. J. (Eds.). (2001). Spatia uncertainty in ecology. New York: Springer-Verlag.

Hurlbert, S. H. (1984). Pseudoreplication and the design of ecological field experiments. Ecological Monographs, 54, 187-211.

Jakubauskas, M. E., Lulla, K. P., \& Mausel, P. W. (1990). Assessment of vegetation change in a fire-altered forest landscape. Photogrammetric Engineering and Remote Sensing, 56, $371-377$.

Jean, C., Schrag, A. M., Bennetts, R. E., Daley, R., Crowe, E. A., \& O'Ney, S. (2004). Vita Signs Monitoring Plan for the Greater Yellowstone Network: Phase III Report. Bozeman, Montana: National Park Service, Greater Yellowstone Network.

Jumikis, A. R. (1996). Thermal soil mechanics. New Brunswick, New Jersey: Rutgers University Press.

Justice, C., Vermote, E., Townshend, J., DeFries, R., Roy, D., Hall, D., et al. (1998). The Moderate Resolution Imaging Spectroradiometer (MODIS): Land remote sensing for global change research. IEEE Transactions on Geoscience and Remote Sensing, 36, 1228-1249.

Key, C. H., \& Benson, N. C. (2005). Landscape assessment: Remote sensing of severity, the normalized burn ratio; and ground measure of severity, the composite burn index. In D. C. Lutes, R. E. Keane, J. F. Caratti, C. H. Key, N. C. Benson, \& L. J. Gang (Eds.), FIREMON: Fire effects monitoring and inventory system Ogden, Utah: USDA Forest Service, Rocky Mountain Res. Station.

Kistler, R., Kalnay, E., Collins, W., Saha, S., White, G., Woollen, J., et al. (2001). The NCEP_ NCAR 50-year reanalysis: Monthly means CD-ROM and documentation. Bulletin of the American Meteorological Scoiety, 82, 247-268.

Legendre, P. (1993). Spatial autocorrelation: Trouble or new paradigm. Ecology, 74 $1659-1673$.
Lichstein, J. W., Simons, T. R., Shriner, S. A., \& Franzreb, K. A. (2002). Spatial autocorrelation and autoregressive models in Ecology. Ecological Monographs, 72, 445-463.

Littell, R. C., Milliken, G. A., Stroup, W. W., Wolfinger, R. D., \& Schabenberger, O. (2006). SAS for mixed models, (second edition) Cary, North Carolina: SAS Institute Inc.

Lobell, D. B., Hicke, J. A., Asner, G. P., Field, C. B., Tucker, C. J., \& Los, S. O. (2002). Satellite estimates of productivity and light use efficiency in United States agriculture, 198298. Global Change Biology, 8, 722-735.

Lynch, H. J., Renkin, R. A., Crabtree, R. L., \& Moorcroft, P. R. (2006). The influence of previous mountain pine beetle (Dendroctonus ponderosae) activity on the 1988 Yellowstone fires. Ecosystems, 9, 1318-1327.

Malmström, C. M., Thompson, M. V., Juday, G. P., Los, S. O., Randerson, J. T., \& Field, C. B. (1997). Interannual variation in global scale net primary production: Testing model estimates. Global Biogeochemical Cycles, 11, 367-392.

Marris, E. (2007). What to let go. Nature, 450, 152-155.

Monteith, J. L. (1972). Solar radiation and productivity in tropical ecosystems. Journal of Applied Ecology, 9, 747-766.

National Climatic Data Center (NCDC) (2004). State of the Climate. Asheville, North Carolina: National Oceanic and Atmospheric Administration.: NCDC Climate Services Branch (http://lwf.ncdc.noaa.gov/oa/climate/research).

Nemani, R., Hashimoto, H., Votava, P., Melton, F., Wang, W., Michaelis, A., et al. (2009). Monitoring and forecasting protected area ecosystem dynamics using the Terrestrial Observation and Prediction System (TOPS).Remote Sensing of Environment, 113, 1497-1509 (this issue)

Olson, R. J., Scurlock, J. M. O., Cramer, W., Parton, W. J., \& Prince, S. D. (1997). From Sparse Field Observations to a Consistent Global Dataset on Net Primary Production (IGBPDIS Working Paper No. 16). Toulouse, France: IGBP-DIS.

Openshaw, S., \& Alvanides, S. (1999). Applying geocomputation to the analysis of spatial distributions. In P. A. Longley, M. F. Goodchild, D. J. Maguire, \& D. W. Rhind (Eds.), Geographical Information Systems, second edition Principles and Technical Issues, Vol. 1. (pp. 267-282). New York: Wiley.

Pace, K. R., \& Barry, R. P. (1997). Fast cars. Journal of Statistical Computation and Simulation, 59, 123-145.

Pace, K. R., \& Barry, R. P. (1997). Sparse spatial autoregressions, statistics and probability. Letters, 33, 291-297.

Potter, C. S. (1999). Terrestrial biomass and the effects of deforestation on the global carbon cycle. BioScience, 49, 769-778.

Potter, C. S., Bubier, J., Crill, P., \& LaFleur, P. (2001). Ecosystem modeling of methane and carbon dioxide fluxes for boreal forest sites. Canadian Journal of Forest Research, 31, $208-223$.

Potter, C. S., Gross, P., Genovese, V., \& Smith, M. -L. (2007). Net primary productivity of forest stands in New Hampshire estimated from Landsat and MODIS satellite data. Carbon Balance and Management, 2, 9. doi:10.1186/1750-0680-2-9 (m-l.).

Potter, C. S., Klooster, S. A., \& Brooks, V. (1999). Interannual variability in terrestrial net primary production: Exploration of trends and controls on regional to global scales. Ecosystems, 2, 36-48.

Potter, C. S., Klooster, S., Huete, A., \& Genovese, V. (2007). Terrestrial carbon sinks for the United States predicted from MODIS satellite data and ecosystem modeling. Earth Interactions, $11,1-21$.

Potter, C. S., Klooster, S., Myneni, R., Genovese, V., Tan, P., \& Kumar, V. (2003). Continental scale comparisons of terrestrial carbon sinks estimated from satellite data and ecosystem modeling 1982-98. Global and Planetary Change, 39, 201-213.

Potter, C. S., Randerson, J. T., Field, C. B., Matson, P. A., Vitousek, P. M., Mooney, H. A., et al. (1993). Terrestrial ecosystem production: A process model based on global satellite and surface data. Global Biogeochemical Cycles, 7, 811-841.

Priestly, C. H. B., \& Taylor, R. J. (1972). On the assessment of surface heat flux and evaporation using large-scale parameters. Montana Weather Review, 100, 81-92.

Reeves, M. C., Winslow, J. C., \& Running, S. W. (2001). Mapping weekly rangeland vegetation productivity using MODIS algorithms. Journal of Range Management, 54, 90- 105.

Rodman, A., Shovic, H. F., \& Thoma, D. (1996). Soils of Yellowstone National Park (YCR-NRSR96-2). Yellowstone National Park, Wyoming: Yellowstone Center for Resources.

Roy, D. P., Boschetti, L., \& Trigg, S. N. (2006). Remote sensing of fire severity: Assessing the performance of the Normalized Burn Ratio. IEEE Geoscience and Remote Sensing Letters, $1,112-116$

Running, S. W., Nemani, R., Heinsch, F., Zhao, M., Reeves, M., \& Hashimoto, H. (2004). A continuous satellite-derived measure of global terrestrial primary production. BioScience, 54, 547-560.

Running, S. W., Zhao, M., Heinsch, F. A., \& Nemani, R. (2007). Terrestrial gross and net primary production (GPP/NPP) global data set. (ftp://ftp.iluci.org/Land_ESDR/GPPNPP_Running_whitepaper.pdf).

Ryan, M. G., Binkley, D., \& Fownes, J. H. (1997). Age-related decline in forest productivity: Pattern and process. Advances in Ecological Research, 27, 213-262.

Schwarz, G. (1978). Estimating the dimension of a model. Annals of Statistics, 6(2), $461-464$.

Sone, A., \& Griffith, D. (1995). Trade-offs associated with normalizing constant, computational simplifications for estimating spatial statistical models. Journal of Statistical Computation and simulation, 51, 165-184

Tanaka, S., Kimura, H., \& Suga, Y. (1993). Preparation of a 1:25000 Landsat map for assessment of burnt area on Etaijima Island. International Journal of Remote Sensing, $4,1731$.

Tomback, D. F., Arno, S. F., \& Keane, R. E. (Eds.). (2001). Whitebark Pine Communities: Ecology and restoration Washington, D.C.: Island Press.

Turner, M. G., Tinker, D. B., Romme, W. H., Kashian, D. M., \& Litton, C. M. (2004). Landscape patterns of sapling density, leaf area, and aboveground net primary production in postfire lodgepole pine forests, Yellowstone National Park (USA). Ecosystems, 7, 751-775. 
Waring, R. H., \& Schlesinger, W. H. (1985). Forest ecosystems: Concepts and management. Orlando, Florida: Academic Press

White, J., Ryan, K., Key, C., \& Running, S. (1996). Remote sensing of fire severity and vegetation recovery. International Journal of Wildland Fire, 6, 125-136.

Wiens, J. A. (2002). Predicting species occurrences: Progress, problems and prospects. In J. M. Scott, P. J. Heglund, F. Samson, J. Haufler, M. Morrison, M. Raphael, \& B. Wall (Eds.), Predicting species occurrences: Issues of accuracy and scale (pp. 739-749). Covelo, California: Island Press.

Zhang, L., Gove, J. H., \& Heath, L. S. (2005). Spatial residual analysis of six modeling techniques. Ecological Modeling, 186, 154-177.
Zheng, D., Prince, S., \& Wright, R. (2003). Terrestrial net primary production estimates for $0.5^{\circ}$ grid cells from field observations - A contribution to global biogeochemical modeling. Global Change Biology, 9, 46-64.

Zimmerman, D. (1989). Computationally exploitable structure of covariance matrices and generalized covariance matrices in spatial models. Journal of statistical computation and simulation, 32, 1-15. 